\title{
Antecedents for Public Service Motivation of Indonesian Public Servants: A Case Study in Padang, West Sumatera
}

\author{
Syamsir \\ Senior Lecturer of The State University of Padang, Indonesia \\ (syamsirsaili@yahoo.com)
}

\begin{abstract}
The study literatures on Public Service Motivation (PSM) have grown tremendously over the past two decades. However there are still many questions remain unanswered in regards to antecedents for the PSM. Besides, most of PSM theories often ignore cultural dimensions in their analysis. This study was designed to investigate the application of the PSM theories in Indonesia, specifically in Padang, West Sumatera. The objective of this study is to test the existing PSM argument related to the antecedents for PSM levels among employees. Using the t-test and Anova on responses by 471 respondents of public sector employees, this study tested the antecedents for PSM among the employees. The findings of this study indicated that some of socio-demographic, social institution, and organisational factors are significantly correlated to the level of PSM, but some of them are not. The results of this study imply that PSM theory is not cross-culturally viable.

Key Words: PSM, public servants, antecedents
\end{abstract}

\section{Introduction}

The study of PSM has become one of the studiesin public administration that is very attractive for researchers in the last decades. Perry and Porter (1982), for instance, have proposed an agenda of research to correct the understanding of motivation in public sector organization. Unfortunately, there are only a few studies that have been able to meet the agenda, whereas studies on PSM are very crucial and an important topic that should get more attention from researchers in the public sector such as the case study of PSM in Indonesia. Studies related to the PSM among employees in Indonesia have not yet become serious concern among the researchers.

Perry and Wise (1990) have defined PSM as 'an individual's predisposition to respond to motives grounded primarily or uniquely in public institutions and organizations'. Based on rational, norm-based and affective ground, Perry (1996) found four dimensions of PSM: attraction to policy making, commitment to the public interest and civic duty, compassion, and self-sacrifice. In addition, Crewson (1997) defined the PSM as an individual service orientation that is useful for society, the orientation of helping others, and the feeling of accomplishment as intrinsic or service orientation. On the other side, Vandenabeele (2007) defined PSM as "the beliefs, values, and attitudes that go beyond self-interest and organizational interest, that concern the interest of a larger political entity and that motivate individuals to act accordingly whenever appropriate".

Based on the studies that have been conducted in some developed countries, PSM were found to have significant correlations with the success of employees or organizations to achieve their objectives. Some researchers have put their attention and look at the importance of studies on PSM.

However, the studies so far were conducted more in the developed countries, both in Western, such as United States, and other developed countries. Perry and Wise (1990), for example, found that PSM is determined by the diverse backgrounds of individuals, among other things, associated with demographic characteristics. On the other hand, Choi (2001) who studied PSM in Korea concluded that the behavioral implications of PSM empirically confirmed in the United States also 
exist in Korea. Choi finally suggests that the theory of PSM may be cross-culturally viable.

In general, the construction of public service motivation in each individual can be affected by various factors such as economic, social, educational, ideological, and other demographic factors. Pandey and Stazyk (2008) summarized three antecedents (determinants) for public service motivation: socio-demographic, social institution, and organizational antecedents. Sosiodemographic included age, education, and sex. Social institution consisted of family socialization, religious socialization, and professionalism. While organizational antecedents included organisational culture, bureaucracy red-tape, the level of hierarchy, and tenure.

In addition, based onhis study, Perry (1997) found that public service motivation is influenced by the diverse backgrounds of individuals, particularly demographic correlates. It means that demographic aspects will determine individuals to perform a high or low motivation in public service. While Lewis dan Frank (2002) has also reviewed the interests of the American people to the public sector. In their study they found that both individual demographic characteristicsand the opportunity to become a useful person to society and their importance to the various quality of work have influenced their interest in working in the public sector.

However, the research finding in the developed countries, as stated above, certainly can not be generalized to the case and the PSM among the civil servants in other countries, especially the third world country like Indonesia, where the context of the countries and the characteristics of the employees might be different compared to those in the West in terms of demographic conditions, culture, religious (belief), etc.

\section{Method}

This study used quantitative method. The data in this study were collected through questionnaires distributed to respondents from several public sector employees in Padang City, West Sumatera Indonesia. The instrument of this study involves averaging the score on a set of PSM items, scored from 1 to 5 ( 1 for 'strongly disagree' to 5 for 'strongly agree') for positive items and from 5 to 1 for the reversed items. The items used in this study referred to Perry's subscales of PSM dimension and measures.

The target population for this study focused on all civil servants (PNS) in local government institutions in Padang West Sumatra. The sample for this study were determined through multistage random sampling.Out of 600 questionnaires distributed in this study, there are only 471 respondents who give feedback. The data in this study were doubly entered to check for errors. $T$ testand Anova test were used to identify and to analyze the antecedents of PSM among the public servants.

\section{Result And Discussion}

Studies on PSM in developed countries, as conducted by Pandey dan Stazyk (2008), Perry (1997 and 2000), Lewis and Frank (2002), and others, generally found that there were significant correlations between PSM and socio-demographic, social institution, and organisational factors. Based on the various research findings, the objective of this study is to identify the antecedents of the PSM among civil servants in Padang West Sumatra. To meet this objective the hypothesis stated that: There are significant correlations between PSM and socio-demographic, social institution, and organisational factors among public servants in Padang, West Sumatra. Testing on this hypothesis has been made by using t-test and Anova test, as seen in table 1. 
Table 1Correlation Between PSM and Socio-demographic, Social Institution, and Organisational Antecedents

\begin{tabular}{|l|l|l|l|}
\hline Socio-Demographic & T-Test & Anova & Sig. \\
\hline Age & & 1.883 & 0.130 \\
\hline Sex & -14.944 & & $0.000^{*}$ \\
\hline Marital Status & 10.183 & & $0.000^{*}$ \\
\hline Educational Level & & 1.053 & 0.369 \\
\hline Income & & 124.400 & $0.000^{*}$ \\
\hline Political ideology & & 5.756 & $0.001^{*}$ \\
\hline Social Institution & & & \\
\hline Family Socialization & & 35.199 & $0.000^{*}$ \\
\hline Religious Socialization & & 8.544 & $0.000^{*}$ \\
\hline Religious Application & & 4.481 & $0.012^{*}$ \\
\hline Involvement in Voluntarism & & 0.489 & 0.614 \\
\hline Professionalism & & 1.543 & 0.215 \\
\hline Organisational Antecedents & & & \\
\hline Job Position & -18.133 & & $0.000^{*}$ \\
\hline Tenure & $p \leq 0.05$ & & \\
\hline
\end{tabular}

As we can see in Table 1, the level of PSM was only significantly correlated to sex, marital status, income, andpolitical ideology for socio- demographic antecedents. While age and education were not correlated to the level of PSM. Besides; the level of PSM was only significantly correlated to the aspect of family socialization, religious socialization, and the application of religious teachings for social institution antecedents. While employee involvement in voluntary activities and professionalismwere found to have no relationship with the level of PSM. Furthermore, the level of PSM was found only significantly correlated to job position and tenure for organisational antecedents.This means that the differences in age, education level, employee involvement in volunteer activities, and professionalism of the employee will not result in differences in the level of PSM.However, the differences in gender(sex), marital status, income, political ideology, family socialization, religious socialization, the application of religious teachings, job positions, and tenurewere expected to be factors taken into account in determining higher or lower levels of PSM among employees. In other words,these aspectscould be considered in determining whether a person will have a higher or lower level of PSM compared to others.

Some findings of this study found a number of similarities with the findings made by the previous researchers. In previous studies, Perry (1997) found that levels of PSM among employees was influenced by various factors of an individual in respect of a number of things, such as professional identification, political ideology, and demographic correlates, including income and education level. Perry also found that PSM was significantly related to age, 
whereas this study did not find the relationship between age and PSM. These are some of the differences found in terms of socio-demographic factors compared to the study made by Perry.

The findings of this study are also consistent with the findings of Perry, Brudney, Coursey, and Littlepage (2008) who studied 525 volunteers in the United States which found that PSM was significantly related to the socialization of the family, religious activities. Interviews that they do in depth suggests the importance of both the transcendent value, such as spirituality, doing good for others, and a change of life, in the development of public service motivation. Almost all of the respondents said that they have a religious or spiritual reasons for their service activities. This also supports the argument of this study that family education and religious education in the life of a person found to be influential on the level of employee motivation for doing good services.

However, the finding of this study shows that the PSM does not have a significant relationship with the involvement in volunteer activities. Houston (2006), based on data from 1,796 respondents from the 2002 General Social Survey, found that those with high PSM is more likely to volunteer.Similarly, findings of Perry, Brudney, Coursey, and Littlepage (2008) stated that the voluntary nature in the youth should be cause someones to be more voluntary and had a higher PSM when they are adults. This means that the more frequently an individual involved in a variety of volunteer activities, the more likely that they will be able to build attitudes and behavior of altruism and patriotism which is fundamental to increase the level of PSM. But, unfortunately, this study failed to proof this hypothesis. The level of PSM does not have a significant relationship with the involvement in volunteer activities among Indonesian public servants, especially in Padang,West Sumatera.

This study also found that professionalism of an employee does not have a significant relationship with the level of PSM. This finding was quite different from the study of Mosher (1982) who found that professional responsibility was thought to be positively related toPSM level. This study also differs from the findings ofPerry (1997) who found that levels of PSM among employees were affected by the diverse backgrounds of the individual professionalism. The same study of Moynihan and Pandey (2007) also found that professionalism was significantly associated with PSM level among the employees.

Besides, this study also found that the level of PSM was only significantly correlated to job position and tenure, while the grade/job level of employees was found to have no relationship with the level of PSM. The finding of this study was consistent with the study made by Moynihan and Pandey (2007), Camilleri (2007) and Bright (2009).Moynihan and Pandey (2007)found that PSM is strongly and positively related to the level of employee hierarchy. While Camilleri (2007) also found that employment grade has a positive relationship with the PSM level. These findings suggests that while someone expect that individuals move to higher organizational hierarchy then their need to serve in the public service will get stronger. The findings are also in line with the findings of Bright (2005) who found that public service motivation is significantly related to the management level.

This can be explained with some reasons that the level of PSM level among public servants in this study area is in fact influenced more by income level as well as the other factors such as marital status, 
political belief, sex and social institutional factors related to family socialization, religious socialization, and application of religious teachings in everyday life days. Similary, job position in the case of Indonesian employees is closely associated with reward or remuneration received by an employee, whether extrinsic orintrinsic rewards.

Therefore, it is desirable that an employee who holding positions is more motivated in providing services to the public than those who not, because they are holding positions will be motivated by extrinsic rewards they will receive. As is known that the need for money for the people in the third world or developing country like Indonesia has become the most important motivator in their lives. Hence, it is appropriate that if the position can cause the spirit or higher motivation to an employee in providing services to the public.

\section{Conclusion}

Refer to the data analysis in this study, it can be concluded that some of the findings of this study are consistent with previous research findings so that they can reinforce the theory related to PSMthat has been made by many researchers in developed countries, especially in the West. But in the other hand, some findings of this study are inconsistent with previous findings. In addition, several findings in terms of PSM also imply that the level of the PSM and its determinants among the employees in developed countries in the West is also assumed to exist among employees in any area of the country. A few scholars argued that the theory of PSM might be cross-culturally viable. But, this conclusion is not entirely true and does not occur in the case of PSM among public servants in Padang West Sumatra which proves the contrary in some aspects.Thus, in general, it can be concluded that the theories related to the study of the PSM in various public sectors in developed countries could not be generalized, especially for the case developing or third world countries which have social characteristics, cultural, economic, ideological, religious, and other values which might be different from one to another.

\section{Acknowledgment}

This article is part of a research project conducted in Padang in 2013 over the cost of the sponsorship of the State University of Padang, Indonesia.

\section{References}

[1] Bright, Leonard. (2005). Public Employees With High Levels of Public Service Motivation: Who Are They, Where Are They, and What do They Want? Review of Public Personnel Administration. June 2005 25: 138-154.

[2] (2009). Why Do Public Employees Desire Intrinsic Nonmonetary Opportunities?. Public Personnel Management. Volume 38 No. 3 Fall

[3] Camilleri, Emanuel. (2007). Antecedents Affecting Public Service Motivation. Personnel Review, 2007, Vol. 36, Issue: 3 pp. 356 - 377.

[4] Choi, Young Joon. (2001). A Study of Public Service Motivation: The Korean Experience. Ph.D. Dissertation, University of Idaho.

[5] Crewson, P.E. (1997). Public Service Motivation: Building Empirical Evidence of Incidence and Effect. Journal of Public Administration Research and Theory (J-PART). (4) p. 499-518.

[6] Houston, David J. (2006). "Walking the Walk" of Public Service Motivation: Public Employees and Charitable Gifts of Time, Blood, and Money. Journal of Public Administration Research and Theory. 16(1): 67-86

[7] Lewis, Gregory B. and Sue A. Frank. (2002). Who Wants to Work for the Government. Public 
Administration Review. July/Agust 2002, Vol. 62, No. 4. p. 395-404.

[8] Moynihan, D.P. and Pandey, S.K. (2007). The role of organizations in fostering public service motivation. Public Administration Review. Vol. 67 No. 1, pp. 40-53.

[9] Mosher, F.M. (1982). Democracy and the Pub-lic Service. $2^{\text {nd }}$ Ed. New York:Oxford University Press.

[10] Pandey, Sanjay K. and Edmund C. Stazyk. (2008). Antecedent and Correlates of Public Service Motivation dalam Perry, James L., and Annie Hondeghem, eds. 2008. Motivation in Public Management: The Call of Public Service. Oxford: Oxford University Press.

[11] Perry, James, L. (1996). Measuring Public Service Motivation: An Assessment of Construct Reliability and Validity. Journal of Public Administration Research and Theory (J-PART). Volume 6, No. 1, p. 5-23

[12] _ (1997). Antecedents of Public Service

Motivation. Journal of Public Administration
Research and Theory (J-PART). April 1997. p. 181-197.

[13] Perry, James, L. and Lois Recascino Wise. (1990). The Motivational Bases of Public Service. Public Administration Review 50 (May/June): 367-373.

[14] Perry, James L., and Porter, Lyman W. (1982). Factors Affecting the Context for Motivation in the Public Sector. Academy of Management Review 7 (Jan.):89-98.

[15] Perry, James L., Jeffrey L. Brudney, David Coursey, and Laura Littlepage. (2008). What Drives Morally Committed Citizens? A Study of the Antecedents of Public Service Motivation. Public Administration Review. May-June 2008: 445-458.

[16] Vandenabeele, Wouter. (2007). Toward A Public Administration Theory of Public Service Motivation: An institutional approach. Public Management Review. Vol. 9 Issue 4; 2007; 545 - 556 